\title{
Educación Literaria y Estética en la enseñanza primaria: propuesta didáctica para animar a leer desde la educación física
}

Literatura eta estetika hezkuntza lehen hezkuntzan: gorputz hezkuntzatik irakurketa sustatzeko proposamen didaktikoa

Literary and aesthetic education in primary education: a didactic proposal to promote reading from physical education

\author{
Miǵuel Sánchez García \\ Universidad de Las Palmas de Gran Canaria \\ miguel.sanchez@ulpgc.es \\ https://orcid.org/0000-0002-3794-3980
}

Recibido / Noiz jaso den: 30/06/2021

Aceptado / Noiz onartu den: 23/10/2021

\begin{abstract}
Resumen
Expongo una experiencia de aula vinculada a la asignatura Educación Literaria y Estética en la enseñanza primaria (cuarto curso del Grado de Educación Primaria). Esta se ha desarrollado con alumnado de la mención de Educación Física. He conjugado la animación lectora con actividades relacionadas con el cuerpo y las emociones propiciando un enfoque competencial. El objetivo es integrar dos disciplinas aparentemente lejanas (Literatura y Educación Física) con propuestas que favorezcan la creación de actividades imaginativas, evitando la "parcelación» de los futuros docentes en compartimentos estancos. No se pretende dar a conocer libros de literatura relacionados con el deporte, sino propiciar dinámicas de aula que trabajen tanto el goce lector y estético como el desarrollo emocional, físico y creativo. Los resultados son positivos, pues se ha favorecido tanto una visión interdisciplinar y creativa de los futuros docentes como el trabajo en equipo. Todo ello redunda en un aprendizaje más abierto y participativo.
\end{abstract}

\section{Palabras clave}

Didáctica; creatividad; animación a la lectura; educación física; formación del profesorado.

\section{Sumario}

1. IntRoducción. 2. MÉtodo. 3 Resultados. 4 Conclusiones. RefERencias. 


\begin{abstract}
Laburpena. Lehen Hezkuntzan Literatura eta Estetika Hezkuntza gaiari lotutako ikasgelako esperientzia aurkezten dut (Lehen Hezkuntzako Graduko laugarren maila). Gorputz Hezkuntzako aipameneko ikasleekin garatu da hori. Irakurketa animazioa gorputzarekin eta emozioekin lotutako jarduerekin konbinatu dut, gaitasun ikuspegiaren alde eginez. Helburua itxuraz urrun dauden bi diziplina (Literatura eta Gorputz Hezkuntza) irudimenezko jarduerak sortzea bultzatzen duten proposamenekin integratzea da, etorkizuneko irakasleen "banaketa» konpartimentu estankotan saihestuz. Ez da kirolarekin lotutako literatura liburuak ezagutzera eman nahi, irakurketaren eta gozamen estetikoaren eta garapen emozionala, fisikoa eta sortzailea lantzen duten ikasgelako dinamikak sustatzeko baizik. Emaitzak positiboak dira, etorkizuneko irakasleen eta talde-lanaren diziplina arteko eta sormenezko ikuspegia sustatu baitu. Hori guztia ikaskuntza irekiagoa eta parte-hartzaileagoa bilakatzen da.
\end{abstract}

Gako hitzak. Didaktika; sormena; irakurketarako bultzada; gorputz hezkuntza; irakasleen prestakuntza.

\begin{abstract}
I present a classroom experience linked to the subject Literary and Aesthetic Education in primary education (fourth year of the Primary Education Degree). This has been developed with students of the mention of Physical Education. I have combined reading animation with activities related to the body and emotions, promoting a competence approach. The objective is to integrate two seemingly distant disciplines (Literature and Physical Education) with proposals that favor the creation of imaginative activities, avoiding the "division" of future teachers in watertight compartments. It is not intended to publicize literature books related to sports, but rather to promote classroom dynamics that work both on reading and aesthetic enjoyment as well as on emotional, physical and creative development. The results are positive because both an interdisciplinary and creative vision of future teachers and teamwork have been favored. All this results in a more open and participatory learning.
\end{abstract}

Keywords. Didactics; creativity; reading animation; physical education; teacher training.

\section{Introducción}

La formación del profesorado de primaria, de los futuros maestros y maestras, ha de fomentar el docente integral, capaz de entender y desarrollar la enseñanza como una formación abierta, dinámica y creativa, entendida esta última característica, siguiendo lo expuesto por Rebel (2000, p. 88), como la capacidad de «desarrollar la fantasía en todos los ámbitos posibles», como «la tendencia a la experimentación», que creemos fecunda y necesaria en todos los campos. A ello debemos sumar el adecuado manejo y desarrollo de las emociones en los infantes de esta etapa, aspecto que ha ido ganando peso en el currículo (2014) y que debe afrontarse desde todas las áreas. En el caso de Canarias, donde se desarrolla nuestra labor, la Consejería de Educación, Cultura y Universidades, al amparo de la LOMCE (2013), integra en el itinerario de Primaria, dentro de las asiǵnaturas de libre configuración autonómica, Educación Emocional y para la Creatividad, que toma como base la inteligencia emocional y la creatividad para propiciar el bienestar de los niños y niñas. He tenido en cuenta estos aspectos para la realización de una experiencia de aula vinculada a la asignatura Educación Literaria y Estética en la enseñanza primaria (cuarto curso del grado). 
Se ha desarrollado con alumnado de la mención de Educación Física. En ella han participado cuarenta y ocho alumnos y alumnas. He conjugado la animación lectora con actividades relacionadas con el cuerpo y las emociones propiciando un enfoque competencial, creativo. He querido integrar dos disciplinas aparentemente lejanas (Literatura y Educación Física) con propuestas que favorezcan la creación de actividades imaginativas, evitando la «parcelación» de los futuros docentes en compartimentos estancos. Para ello, he tomado como referencia los criterios de evaluación de tres áreas de la etapa de primaria: Lengua Castellana y Literatura, Educación Física y Educación Emocional y para la Creatividad. Me he trazado, entre otros objetivos, que el alumnado recuerde:

a) Que la educación en la etapa de primaria no está formada por áreas aisladas y que la suma de todas ellas propicia el desarrollo de las diferentes competencias.

b) Que una mirada abierta, independientemente de que trabajes en un proyecto junto a otros docentes, facilita una visión integradora de la enseñanza y aprendizaje en la etapa.

\section{Método}

Conde et al. (1998) ya hablaba de las ventajas de la interdisciplinariedad entre las áreas de Educación Física y Lenǵua Castellana y Literatura. Desde un enfoque competencial (trabajo conjunto de las diferentes áreas), busco en el alumnado del Grado de Primaria no solo la puesta en práctica de dinámicas de aula, sino también el goce de la experiencia en los discentes para que el maestro o maestra en formación sea capaz de involucrarse en la animación lectora cuando sea docente. Las tareas que propongo al alumnado recogerían, en cierta medida, las propuestas de autores como Parra Luque (2008), Ruiz Omeñaca (2009 y 2011), Guimaraes (2009 y 2017) o Tabernero Sánchez et al. (2016). No se pretende dar a conocer libros de literatura relacionados con el deporte sino propiciar dinámicas de aula que trabajen tanto el goce lector y estético como el desarrollo emocional, físico y creativo. Para ello:

2.1. Comento primeramente aspectos de los diferentes currículos (Educación Física, y Lengua Castellana y Literatura), al que añado, como ya adelanté, una materia propia de la Comunidad Autónoma de Canarias: Educación Emocional y para la Creatividad. Todos ellos tienen como referencia en Canarias el Decreto 89/2014, de 1 de agosto. Pretendo con ello dar a conocer, desde el punto de vista legislativo, las posibilidades de actuación integral en el aula. Creo interesante recordarles que hay un objetivo de la etapa de primaria que vincula a todas las áreas (artículo 7 del Real Decreto 126/2014, de 28 de febrero, recogido en Cana- 
rias en el Decreto 89/2014, de 1 de agosto) que adquiere una especial relevancia en nuestra propuesta:

El afianzamiento del autoconocimiento, la autoestima, la gestión de las emociones y los hábitos de cuidado y salud corporales propios de un estilo de vida saludable en pro del desarrollo personal y social (p. 21911).

Trabajo, como he comentado, con alumnado de la mención de Educación Física y busco una mirada «abierta» del currículo que los acerque a la literatura desde su propia área. Me centro, para ello, primero, en dar a conocer aquellos aspectos más significativos de la contribución a los objetivos de la etapa de enseñanza primaria vinculados a cada una de las áreas seleccionadas (2014). Destaco, en relación a las actividades que se van a proponer, su visión globalizadora:

\section{- Lengua Castellana y Literatura:}

a. Visión integradora.

b. Dimensión comunicativa, como instrumento de comunicación social y de expresión artística.

c. La lengua materna se pone al servicio del desarrollo integral del alumnado -saber, saber hacer, saber ser: desarrollo holístico del alumnado.

- Educación Física:

a. Convivencia en el desarrollo de las tareas motrices.

b. Prevención y la resolución pacífica de los posibles conflictos manteniendo actitudes contrarias a la violencia.

c. No discriminación de personas con discapacidad en las prácticas de la actividad física o el desarrollo de sus capacidades afectivas en los distintos ámbitos de la personalidad y en sus relaciones con las demás personas, evitando los prejuicios de cualquier tipo y estereotipos sexistas.

\section{- Educación Emocional y para la Creatividad:}

a. Comprensión y la valoración de experiencias emocionales prestando atención a las sensaciones del cuerpo.

b. Capacidad de relacionarse activamente y saber comprender a las demás personas.

c. Resolución de conflictos desde el diálogo y la negociación, desarrollando habilidades sociales (empatía y asertividad).

Seguidamente, selecciono los criterios de evaluación más relevantes para la dinámica a realizar, pues en la LOMCE (2013) adquieren el protagonismo que antes tenían los objetivos de cada asignatura (circunscritos ahora a los de etapa) y definen las metas que debemos alcanzar. Debemos tener en cuenta que el área de Lengua Castellana y Literatura (en adelante LCL) trasciende a la propia asig- 
natura, pues la lengua es vehículo de comunicación de todas las áreas. Es por ello parte fundamental, como establece el propio currículo, del desarrollo inteǵral y holístico del alumnado. El currículo de LCL establece unos criterios que facilitan nuestra labor, pues son:

Longitudinales, pues la mayor parte de los aspectos que debe conseguir el alumnado no son exclusivos de un nivel determinado, sino que vertebran el proceso de enseñanza y aprendizaje a lo largo de toda la etapa -comprensión lectora, expresión oral y escrita, plan lector...-. A esto se suman una serie de criterios transversales, que proponen aprendizajes comunes a todas las materias -creatividad, expresión de emociones...-, y criterios específicos, muy vinculados a nuestra área -variedad lingüústica- (Decreto, 89/2014, p. 22063).

Me ciño a los relacionados con la literatura que, con diverso grado de intensidad, se establecen para cada nivel de Primaria. Son los criterios 7 y 8 que exponemos a continuación. Escogemos los vinculados a $3^{\circ}$ de primaria, pero son similares en el resto de cursos:

Tabla 1. LCL. 3. ${ }^{\circ}$ de primaria. Criterio de evaluación n. ${ }^{\circ} 7$

7. Dramatizar textos adecuados o adaptados en el contexto escolar, utilizando los recursos de los intercambios orales e iniciándose en el conocimiento de las convenciones del género teatral en sus diferentes fases (planificación, ensayo, ejecución) para favorecer la autonomía, la confianza en las propias posibilidades y mejorar la propia capacidad lingüuística, comunicativa, expresiva, emocional y creativa.

Estándares de aprendizaje evaluables relacionados: $19,103,104$.

\section{Contenidos}

6. Comprensión, memorización o recitado de poemas, canciones, adivinanzas, trabalenguas, breves piezas teatrales, etc. con el ritmo, entonación y dicción adecuados para la mejora de la propia capacidad de expresión y comunicación.

7. Dramatización de situaciones y de textos, y lectura dramatizada de textos literarios para la mejora de los recursos comunicativos personales y el autodescubrimiento personal y emocional.

8. Aplicación de los recursos propios de los intercambios orales.

9. Iniciación en el conocimiento del género dramático y del texto teatral.

10. Interés por expresarse oralmente de una manera adecuada como medio para expresar la propia expresividad, emocionalidad y creatividad.

11. Actitud de respeto hacia los compañeros y compañeras, y colaboración en situaciones de aprendizaje compartido.

COMPETENCIAS: CL, AA, SIEE, GEC

BLOQUE DE APRENDIZAJE II: EL ALUMNADO COMO APRENDIENTE AUTÓNOMO

Nota: Elaboración propia a partir del Currículo de LCL (Decreto 89/2014, 1 de agosto). 
Tabla 2. LCL. $3 .^{\circ}$ de primaria. Criterio de evaluación n.$^{\circ} 8$

8. Crear textos literarios en prosa o en verso partiendo de la lectura expresiva y comprensiva de distintos tipos de textos literarios, tanto en la práctica escolar como en la lectura por propia iniciativa, iniciándose en el reconocimiento y la interpretación de alǵunas de sus convenciones, con la finalidad de apreciar el valor de los mismas y construir significativamente el propio plan lector, buscar una mejora progresiva en el uso de la lengua y descubrir cauces que le ayuden a desarrollar la sensibilidad, la creatividad y el sentido estético.

\begin{abstract}
Estándares de aprendizaje evaluables relacionados: $47,48,57,58$, $59,62,71,97$ $98,99,100$ $101,102,103$ 104.
\end{abstract}

COMPETENCIAS: CL, CD, AA, CEC

BLOQUE DE APRENDIZAJE III: EL ALUMNADO COMO HABLANTE (INTER)CULTURAL

Nota: Elaboración propia a partir del Currículo de LCL (Decreto 89/2014, 1 de agosto).

Con respecto al currículo de Educación Física, nos centramos en los criterios 3 y 4 . Escogemos igualmente los vinculados a $3 .^{\circ}$ de primaria, pero son similares en el resto de cursos:

Tabla 3. Educación Física. $3 .^{\circ}$ de primaria. Criterio de evaluación n.$^{\circ} 3$

3. Utilizar los recursos expresivos del cuerpo y el movimiento para comunicar sensaciones, emociones e ideas de forma espontánea y creativa, así como para seǵuir estructuras rítmicas.

Con este criterio se pretende valorar la capacidad del alumnado para comunicar de forma creativa y comprensible sus sentimientos, emociones, ideas, vivencias, personajes $o$ actos etc., a partir de su motricidad, siendo capaz de transmitir los elementos expresivos con estilo propio.
Estándares de Contenidos aprendizaje evaluables relacionados:
1. Uso y disfrute del cuerpo, del gesto y del movimiento como instrumentos de expresión y comunicación corporal.
$7,8,11,12$. $[\ldots]$
1. Representación de personajes reales y ficticios y sus contextos dramáticos

\section{COMPETENCIAS: CEC}

\section{BLOQUE DE APRENDIZAJE I: REALIDAD CORPORAL Y CONDUCTA MOTRIZ.}

Nota: Elaboración propia a partir del Currículo de LCL (Decreto 89/2014, 1 de agosto). 
Tabla 4. Educación Física. $3 .^{\circ}$ de primaria. Criterio de evaluación n ${ }^{\circ} 4$

4. Aplicar los conocimientos propios de la Educación Física y de otras áreas en situaciones lúdico-motrices, artístico expresivas y físico-motrices.

Con este criterio se pretende verificar si el alumnado es capaz de identificar, comprender y emplear el vocabulario adecuado, tanto de Educación Física como de otras áreas del currículo, para comunicarse en el transcurso de la práctica de juegos motores y actividades artísticoexpresivas (habilidades, bailes, danzas, ritmo...).

Estándares de
aprendizaje
evaluables
relacionados:
$13,14,15,16$,
$28,30,39$.

\section{Contenidos}

1. Identificación y reconocimiento de las habilidades motrices básicas, las nociones topológicas básicas, la higiene corporal, la higiene postural, la respiración, el tono muscular, la relajación, los bailes y danzas de distintas culturas, los juegos infantiles populares y tradicionales.

\section{COMPETENCIAS: GL}

BLOQUE DE APRENDIZAJE I: REALIDAD CORPORAL Y CONDUCTA MOTRIZ.

Nota: Elaboración propia a partir del Currículo de LCL (Decreto 89/2014, 1 de aǵosto).

Con respecto al currículo de Educación Emocional y para la Creatividad, debemos resaltar, como estable el propio currículo, «la idea de transversalidad y globalidad que tiene esta asignatura. Las emociones y la creatividad están presentes en cualquier situación de aprendizaje que se genere en el aula» (Decreto 89/2014, p. 22536). Nos centramos en los criterios 1, 2 y 6. Escogemos igualmente los vinculados a $3 .^{\circ}$ de primaria, pero son similares en el resto de cursos.

Tabla 5. Educación Emocional y para la Creatividad. $3 .^{\circ}$ de primaria. C. E. n. ${ }^{\circ} 1$

1. Percibir las sensaciones corporales asociadas a las experiencias emocionales básicas personales, identificando dichas emociones y nombrándolas para favorecer la conciencia emocional.

Se pretende observar si el alumnado percibe las emociones básicas (alegría, humor, miedo, tristeza, verğtienza, ira, ansiedad, culpa, orğullo, asco, amor...) que experimenta en determinados entornos y sucesos y las relata.

\section{Contenidos}

1. Percepción de las sensaciones corporales.

1.1. Observación e identificación corporal: gestos, mirada, respiración, desplazamiento..., en relación con determinadas situaciones propuestas.

1.2. Vocabulario de sensaciones: respiración pausada-agitada, gestos faciales tensos-relajados, manos sudorosas-secas, agitación-relajación corporal, mirada serena-inquieta...

1.3. Comunicación y relato de las sensaciones.

2. Identificación de las emociones básicas:

2.1. Observación de las emociones en función de las sensaciones corporales producidas.

2.2. Vocabulario básico emocional: alegría, ira, humor, miedo, tristeza, ilusión y vergüienza, ansiedad, culpa, orǵullo, asco, amor.

2.3. Comunicación y relato de las emociones.

$[\ldots]$

COMPETENCIAS: CL, CSC, AA, CMCT

BLOQUE DE APRENDIZAJE I: CONCIENCIA EMOCIONAL

Nota: Elaboración propia a partir del Currículo de LCL (Decreto 89/2014, 1 de agosto). 
Tabla 6. Educación Emocional y para la Creatividad. 3 . $^{\circ}$ de primaria. C. E. n. ${ }^{\circ} 2$

2. Reconocer las emociones propias y las de las demás personas como medio para desarrollar la capacidad de autodescubrimiento personal.

Es intención del criterio comprobar que el alumnado desarrolla su capacidad de indagar en su interior y reconoce sus emociones, descubriéndolas y describiéndolas como algo propio de su personalidad, utilizando el diálogo interno, autoafirmaciones positivas, aceptación de (defectos) virtudes y limitaciones.

\section{Contenidos}

1. Desarrollo de la introspección:

1.1. Uso del diálogo interno.

1.2. Toma de conciencia inmediata de sus propios estados.

1.3. Descripción de sensaciones propias internas mediante lenǵuaje verbal y no verbal.

2. Descubrimiento, reconocimiento y aceptación de sus emociones:

2.1. Percepción y expresión de emociones a través de diferentes lenǵuajes.

2.2. Comprensión de las causas y consecuencias de sus emociones.

2.3. Manejo de sus emociones de manera efectiva y adaptativa.

$[\ldots]$

COMPETENCIAS: CL, CSC, AA,

BLOQUE DE APRENDIZAJE I: CONCIENCIA EMOGIONAL

Nota: Elaboración propia a partir del Currículo de LCL (Decreto 89/2014, 1 de agosto).

Tabla 7. Educación Emocional y para la Creatividad. 3. ${ }^{\circ}$ de primaria. C. E. n. ${ }^{\circ} 6$

6. Experimentar y aplicar principios y estrategias de pensamiento divergente y analógico con el máximo detalle posible, utilizando los múltiples lenguajes como medio para autoafirmar el propio potencial creativo.

\section{Contenidos}

1. Uso del pensamiento divergente.

1.1. Producción de gran cantidad de ideas.

1.2. Análisis, clasificación, seriación, comparación y utilización de diversos criterios y puntos de vista.

1.3. Búsqueda de ideas alternativas, diferentes e inusuales.

1.4. Asociación novedosa y extraña entre ideas.

2. Uso de las técnicas creativas elementales: lluvia de ideas, analogías, ideart, etc.

2.1. Aplicación de las téenicas creativas como herramienta de trabajo individual y ǵrupal

2.2. Manejo de técnicas elementales y de otras más complejas.

3. Puesta en práctica de los múltiples lenguajes de forma creativa.

3.1. Sonorización, composición plástica y dramatización a partir de cuentos, vivencias, temáticas infantiles.

3.2. Producción de textos: cuentos, poemas, chistes, cómics, anuncios publicitarios, etc.

COMPETENCIAS: CL, CSC, AA, CEC

BLOQUE DE APRENDIZAJE III: CREATIVIDAD

Nota: Elaboración propia a partir del Currículo de LCL (Decreto 89/2014, 1 de agosto). 
Pretendo con este primer paso el que el alumnado conozca las diferentes sinergias que pueden darse entre los diferentes currículos. La Educación Física puede aportar y también recoger mucho de lo expuesto en los asociados a las otras áreas. Recordemos, por ejemplo, lo enunciado en los criterios n. ${ }^{\circ} 3$, «utilizar los recursos expresivos del cuerpo y el movimiento para comunicar sensaciones»; y n. ${ }^{\circ}$, "verificar si el alumnado es capaz de identificar, comprender y emplear el vocabulario adecuado, tanto de Educación Física como de otras áreas del currículo, para comunicarse en el transcurso de la práctica de juegoos motores y actividades artístico-expresivas». Hay muchas posibilidades creativas.

2.2. Se muestran algunas obras que narran historias que se pueden abarcar desde diferentes ángulos, en las que el alumnado puede apreciar el yo junto al nosotros o nosotras, las relaciones grupales, la diversidad física y psíquica:

1) Las jirafas no pueden bailar

2) Orejas de mariposa

3) ¡Mi cuerpo es mío!

4) Abrázame

5) Elmer

El primer cuento, Las jirafas no pueden bailar (Andreae y Parker-Rees, 1999), muestra tanto la importancia de la expresión artística como la de no renunciar a nuestros sueños. Cuenta la historia de una jirafa que ama bailar, pero que, en principio, no es aceptada por el resto de animales al presumirse que una jirafa, por sus aptitudes físicas, no puedo hacerlo.

El segundo cuento, Orejas de mariposa (Aguilar y Neves, 2008), cuenta la historia de Mara, que sufre acoso escolar, que ve atacada inicialmente su autoestima, por lo que algunos ven un defecto físico (sus grandes orejas) y que ella termina considerándolo algo positivo.

La tercera historia, ;Mi cuerpo es mío! (ProFamilia y Geisler, 2015), nos expone la necesidad de que los niños y las niñas tomen conciencia de su cuerpo, de evitar y rechazar los contactos no deseados, aunque no sea tarea fácil.

El cuarto cuento, Abrázame (Ciraolo, 2014), trata sobre la importancia del cariño y del respeto, de no tener prejuicios sobre las personas por su aspecto. Narra la historia de un cactus, Felipe, que busca el afecto de los demás.

La última historia, Elmer (McKee, 2018), cuenta las peripecias de un elefante, Elmer, que nace con una característica muy llamativa: es multicolor. Él no quiere ser así, desea ser como los demás, no quiere ser distinto e intenta buscar un remedio para conseguirlo.

Una vez comentadas las historias anteriores, que están en formato álbum ilustrado, se le propone al alumnado:

a) Actividad grupal: propuesta creativa de reescritura de cuentos populares. Se busca, desde un punto de vista metodológico, un aprendizaje signifi- 
cativo (Ausubel, 2002) dentro de un enfoque ǵlobalizador de la enseñanza. Se facilitaría igualmente el desarrollo de las inteligencias múltiples de Gardner (como se citó en Armstrong, 2006), pues se trabajarían, entre otras, la lingüuística, la visual-espacial, la corporal-cinestésica, la intrapersonal y la interpersonal por la dinámica de las actividades propuestas. El alumnado trabaja en grupos heterogéneos (distintos ritmos de aprendizaje). Busco que fluya la confianza y la afectividad. Facilito seis títulos no cerrados. Es decir, los grupos, si lo desean, pueden proponer otros.

1) El gato con botas

2) Hänsel y Gretel

3) La cenicienta

4) El patito feo

5) Caperucita roja

6) El traje nuevo del emperador

De los cuentos presentados, los ǵrupos no eligen El gato con botas y El traje nuevo del emperador. Uno de ellos propone, en cambio, Garbancito.

Apreciamos «Caperucitas» con un enfoque feminista y coeducativo; «Hänseles» $\mathrm{y}$ «Greteles» más deportistas y con mejor dieta; un patito inmigrante con dificultades para su integración; un «Ceniciento» que quiere ir a un baile; o un «Garbancito» que lucha por integrase en su grupo de deporte del colegio y, por extensión, en la sociedad. Exponemos, a título de ejemplo, dos de los trabajos realizados por el alumnado:

\section{Caperucita roja y la «skater granny»}

Caperucita se preparaba en casa para ir a ver a su abuela, una patinadora profesional, en la final de la competición de invierno. De repente, el teléfono sonó y las malas noticias llegaron: la hoja metálica del patín de su abuela se había roto. Su madre se ofreció a forjarle una nueva a tiempo para la competición, aunque sería Caperucita la que tendría que correr para llegar antes del inicio de la competición. Caperucita llevaba varios años en atletismo y seguro que iba a tardar menos tiempo en hacer la entrega.

La madre, la herrera del pueblo, tardó poco más de treinta minutos en forjar la nueva hoja y prepararla para que Caperucita la llevara. Iba con el tiempo justo, así que decidió acelerar su paso, aunque no se percató que un extraño ser la observaba. ¡Un lobo!

Para llegar a tiempo, tenía que atravesar diferentes parajes. Uno de ellos era un barranco escarpado muy próximo a su casa. En el pueblo lo conocían como «El barranco rojo», por el color de la tierra. 
Mientras bajaba el barranco, escuchó a alguien pronunciar su nombre. Una señora aparentemente débil, había caído cerca de unas tuneras. A medida que Caperucita se acercaba, empezó a notar cosas extrañas: no usaba calzado y en sus «pies» tenía demasiado vello. ¡No era una mujer!

Ante esto, decidió ignorar la llamada de ayuda y atravesar el barranco corriendo, pues había perdido un tiempo precioso. El lobo, tras el fracaso, decidió tomar un atajo y preparar la siguiente trampa.

Un río cercano se unía al final del barranco. Este río era de gran caudal y separaba el pueblo de nuestra Caperucita de la gran ciudad. La única forma de cruzarlo era sorteando las piedras del delta que se formaba al final del barranco.

Cuando Caperucita se dispuso a cruzarlo, algo extraño llamó su atención. Mientras pisaba piedra a piedra con cuidado de no caer, en una de las últimas, vio aparecer dos ojos. Asustada, decidió correr.

Cansada de correr, decidió tomar un pequeño descanso y recuperar el aliento en uno de los primeros árboles del frondoso bosque. Tras unos minutos para tranquilizarse, decidió volver a emprender su marcha. En ese momento, escuchó una voz grave que la llamaba. Buscando el origen de la llamada, se dio cuenta que provenía de un sauce, el más alto de todos los árboles del bosque. Cuando se acercó, notó que las ramas se movían e intentaban tocarla. Ella, valerosa, extendió sus manos y, para su sorpresa, un rostro anciano se apareció en el tronco. «Hola, joven muchacha. Me llamo Saucín. Te he visto parada al inicio del bosque y creo que no te has dado cuenta que una extraña criatura te ronda desde tiempo atrás». En este momento, Caperucita comprendió que tanto la señora misteriosa del barranco como la roca con ojos del río debían de ser esa extraña criatura.

Agradecida, se despidió de Saucín y de la precaución que le sugirió, retomando de nuevo el camino señalado para atravesar el bosque.

Poco antes de ver la salida, algo llamó su atención. Oculto tras un matorral, se encontraba la extraña criatura. Caperucita, con todos sus sentidos en alerta, decidió acelerar su paso mientras pasaba cerca del matorral. Al ver que las hojas se movían, echó a correr. A su espalda apareció un lobo con su gran cuerpo lleno de pelos, sus prominentes ojos muy abiertos y una gran boca con grandes y afilados colmillos que empezó a perseguirla gritando: «¡Niña, niña! ¡Dame tu bolsa!». Caperucita, sintiendo que corría peligro, decidió no detenerse y empezó a ziǵzaguear entre los árboles, en busca de la salida. El lobo, concentrado en atrapar a la niña, no vio una raíz que sobresalía del suelo, tropezando y lastimándose las patas.

Caperucita, por fin fuera del bosque, emprendió el último tramo del camino en dirección al estadio donde su abuela competiría.

Su abuela, muy agradecida, se preparaba para competir, a la espera de la actuación de su oponente.

Para sorpresa de todos, una extraña criatura cubierta de pelo y con las patas lastimadas, se dispuso a actuar. ¡Era el lobo! 
Caperucita decidió contarle a su abuela todo lo sucedido durante el camino, causando una gran motivación en la abuela justo antes de su actuación.

En el último segundo de su actuación, las patas del lobo, lastimadas por la caída, flaquearon.

La actuación de la abuela fue magistral. El público no paraba de aclamar su nombre. Los jueces no cabían en su asombro. Fácil fue el veredicto de declararla campeona.

Tras la entrega de premios, la abuela, en agradecimiento a Caperucita, la invitó a merendar.

\section{Hansel y Gretel}

Había una vez una leñadora y su esposa que vivían en el bosque en una humilde cabaña con sus dos hijos, Hänsel y Gretel. Eran muy traviesos y les encantaba comer comida basura y no tener hábitos saludables.

Un día, las madres viendo que ya no eran capaces de alimentarse saludablemente y que los niños llevaban una vida muy sedentaria, se sentaron en la mesa y tomaron una decisión.

- iNo podemos hacer otra cosa! Los dejaremos en el bosque como castigo para que aprendan a comer mejor y a reflexionar sobre su mala alimentación.

Esa misma noche, los pequeños, que no podían dormir del hambre que tenían, oyeron toda la conversación y comenzaron a llorar en cuanto supieron el final que les esperaba. Hänsel, el niño, dijo a su hermana:

-No te preocupes, robaré algunas golosinas antes de marcharnos para poder sobrevivir y volver a casa.

Así que, al día siguiente, fueron los cuatro al bosque. Los hermanos se acostaron junto a una hoguera y no tardaron en quedarse dormidos. Cuando despertaron, no había rastro de sus padres y la pequeña Gretel empezó a llorar.

—No llores Gretel —dijo Hänsel—. He ido dejando golosinas a lo largo de todo el camino. Solo tenemos que esperar a que la Luna salga y podremos ver el sendero que nos llevará a casa.

Pero la Luna salió y no había rastro de las golosinas: se las habían comido las palomas. Así que, ambos anduvieron perdidos por el bosque hasta que estuvieron exhaustos y no pudieron dar ni un paso más del hambre que tenían. Justo entonces, se encontraron con una casa de ensueño hecha de chupachups, cubierta de chocolate y chicle, cuyas ventanas eran de azúcar. Tenían tanta hambre, que enseguida se lanzaron a comer sobre ella. De repente, se abrió la puerta de la casa y salió de ella una anciana que parecía amable.

—Hola, niños. ¿Qué hacéis aquí? ¿Acaso tenéis hambre? 
Los pobres hermanos asintieron con la cabeza.

- ¡Anda, entrad dentro y os prepararé algo muy rico!

La vieja les dio de comer comida basura y les ofreció una cama en la que dormir. Pero, pese a su bondad, había algo raro en ella.

Por la mañana, muy tempranito, cogió a Hänsel y lo encerró en el establo mientras el pobre no dejaba de gritar.

— ¡Aquí te quedarás hasta que engordes! —le dijo.

Con muy malos modos, despertó a Gretel y le dijo que fuese a por agua para preparar mucha comida, pues su hermano debía engordar cuanto antes para poder comérselo.

Entonces, la pequeña se dio cuenta de que no era una anciana, sino... ¡una malvada bruja!

Pasaban los días y la bruja se impacientaba porque no veía engordar a Hänsel, ya que este, cuando le decía que le mostrara un dedo para ver si había engordado, siempre la enganaaba con un huesecillo aprovechándose de su ceguera.

Tras el sedentarismo de los niños, añadido a que no cogían nada de peso, finalmente cayeron enfermos. No obstante, la bruja se cansó de la situación y decidió no esperar más.

—iGretel, enciende el horno que vas a preparar un rico pastel! —ordenó a la niña.

Ella se imaginó algo terrible, y supo que en cuanto se despistara la bruja la arrojaría dentro del horno.

—No sé cómo se hace — dijo Gretel.

— ¡Niña tonta! ¿Quita del medio!

Pero cuando la bruja anciana metió la cabeza dentro de este, la pequeña le dio un buen empujón y cerró la puerta. Acto seguido, corrió hasta el establo para liberar a su hermano. Los dos pequeños se abrazaron y lloraron de alegría al ver que habían salido vivos de aquella horrible situación. Estaban a punto de marcharse, pero se dieron cuenta que habían perdido mucha habilidad y que estaban muy cansados, por lo que el regreso a casa fue bastante largo y reflexivo para ellos.

Llegaron al río y decididos, aunque con mucho miedo, cruzaron este nadando, pues solo querían llegar a casa y estar con su familia. Al otro lado de la orilla, continuaron corriendo hasta que vieron a lo lejos la casa de sus padres, quienes se alegraron muchísimo cuando los vieron aparecer, y más aún, cuando vieron que sus hijos habían aprendido la lección: al comer tantos dulces y engordar, aprendieron que debían comer saludable y hacer un poco de ejercicio. En ese instante, supieron que vivirían el resto de sus días felices conjuntamente, con una vida llena de buenos hábitos y mucho amor.

Esta dinámica seguiría los principios expuestos por Rodari (1979) para el fomento de la creatividad y la escritura lúdica. Como señala Salas Díaz (2008, p. 48), «la escritura creativa pone al alumno ante la necesidad de 
sacar de sí mismo respuestas que satisfagan el enunciado de la actividad, de hacerse a sí mismo, y no a un patrón de escritura». Salas Díaz (2008) expone, en relación al alumnado de ELE, premisas que creemos válidas para la interacción entre áreas:

Las actividades que fomentan la creatividad:

1. Aumentan la velocidad de nuestras reacciones mentales.

2. Estimulan la capacidad de adaptación a circunstancias nuevas.

$[\ldots]$

2. Las actividades lúdicas relajan y ayudan a crear cierta atmósfera de familiaridad entre estudiantes y entre alumnado y profesor.

3. Proporciona, además, formas amenas y variadas de ensayar con la lengua.

$[\ldots]$

6. Las actividades lúdicas son fuente de placer.

[...]

2. Autorreferencialidad: cuando ejercemos la escritura creativa, nuestra atención se vuelca sobre el propio mensaje, y no sobre objetivos externos a él, centrándose en sus mecanismos generadores. (pp. 48-49)

Ello es aplicable no solo al alumnado del Grado de Primaria, al que se le propone modificar desde la libertad un cuento clásico, insertando elementos de su propia área o currículo, sino también, a sus futuros discentes que podrán ver la Educación Física desde una mirada más abierta, más literaria.

b) A partir del cuento resultante, propongo a los diferentes grupos la realización de actividades que propicien los objetivos vinculados a las tres áreas: Educación Física, Emocional y Literaria. Deben tener en cuenta los criterios de evaluación propuestos.

Por ejemplo, en relación con el primer cuento mostrado, Caperucita Roja y la «Skater Granny», el grupo propone:

1. Sesión grupal para identificar las emociones de los personajes.

2. Debate. ¿Cómo nos sentimos? ¿Cómo queremos que nos traten? Compartimos experiencias personales.

3. Competición con diferentes pruebas de habilidad y destreza, por equipos y con puntos.

4. Representación teatral del cuento, centrándose en la dramatización de las emociones reflejadas en el mismo.

5. Salida grupal, para fomentar las habilidades sociales, a la pista de hielo de «Las Arenas» de Las Palmas de Gran Canaria. Ello permitirá al alumnado conocer mejor el deporte del cuento, y experimentarlo. 
En relación con el segundo cuento mostrado, Hänsel y Gretel, el alumnado del grupo propone:

- Relacionadas con las áreas de LCL y Educación Emocional y para la Creatividad

Tabla 8. Actividades LCL y Educación Emocional y para la Creatividad

\begin{tabular}{|c|c|c|c|}
\hline Actividades & ¿Cómo realizaremos la actividad? & $\begin{array}{l}\text { ¿Qué función cumple } \\
\text { el alumnado? }\end{array}$ & Conclusiones \\
\hline $\begin{array}{l}\text { 1. Asamblea } \\
\text { emotiva }\end{array}$ & $\begin{array}{l}\text { El alumnado se sentará en círculo y } \\
\text { el tutor o la tutora leerá el cuento en } \\
\text { voz alta. Una vez leído el cuento, rea- } \\
\text { lizará preǵuntas de comprensión. } \\
\text { Cuestiones: } \\
\text { 1. ¿Qué son las emociones? } \\
\text { ¿Podemos nombrar alǵunas? } \\
\text { 2. ¿Cómo se sintieron los niños } \\
\text { cuando vieron que sus padres no } \\
\text { estaban en el bosque? ¿Alǵuna vez } \\
\text { nos hemos sentido así? } \\
\text { 3. ¿Cómo se sintieron los niños } \\
\text { cuando encontraron la casa de la } \\
\text { bruja llena de comida? ¿Cuándo } \\
\text { nos sentimos muy felices? }\end{array}$ & $\begin{array}{l}\text { El alumnado tendrá } \\
\text { una función activa en } \\
\text { todo momento, como } \\
\text { oyentes e interviniendo } \\
\text { en las cuestiones que } \\
\text { se planteen durante } \\
\text { la sesión. Además, } \\
\text { los niños hablan de } \\
\text { sus emociones y de } \\
\text { la autoestima que } \\
\text { sienten. }\end{array}$ & $\begin{array}{l}\text { Al finalizar la } \\
\text { sesión se le } \\
\text { preguntará al } \\
\text { alumnado: } \\
\text { - ¿Qué les } \\
\text { ha parecido } \\
\text { esta } \\
\text { actividad? } \\
\text { - ¿Les } \\
\text { gustaría } \\
\text { repetirla? }\end{array}$ \\
\hline 2. Roleplay & $\begin{array}{l}\text { Realizaremos una asamblea en la que } \\
\text { los niños y niñas tendrán que elegiir } \\
\text { tres situaciones del cuento para re- } \\
\text { presentar de forma animada. En las } \\
\text { representaciones, podrán utilizar ma- } \\
\text { teriales, incluir diálogos, hacer la re- } \\
\text { presentación mediante mímica, etc. } \\
\text { Situaciones: } \\
\text { 1. Los niños van caminando por el } \\
\text { bosque cuando se encuentran con } \\
\text { la casa de la bruja. (dos alumnos } \\
\text { harán de Hänsel y Gretel). } \\
\text { 2. Gretel empuja al horno a la bruja } \\
\text { mala y sale corriendo a salvar a su } \\
\text { hermano. } \\
\text { 3. Cuando los niños salen de la casa } \\
\text { de la bruja, cruzan el río y se } \\
\text { reencuentran con sus padres. }\end{array}$ & $\begin{array}{l}\text { Los niños tendrán } \\
\text { una función activa y } \\
\text { participativa. Con esta } \\
\text { actividad se promueve: } \\
\text { - la creatividad, } \\
\text { - el compañerismo, } \\
\text { - la comunicación, } \\
\text { - la cooperación... }\end{array}$ & $\begin{array}{l}\text { Al finalizar } \\
\text { la actividad, } \\
\text { se les } \\
\text { preǵuntará: } \\
\text { - ¿Qué } \\
\text { personaje } \\
\text { les ha } \\
\text { gustado más } \\
\text { interpretar? } \\
\text { - ¿Qué otro } \\
\text { cuento les } \\
\text { gustaría } \\
\text { recrear? }\end{array}$ \\
\hline
\end{tabular}

Nota: Elaboración propia a partir del trabajo realizado por el alumnado. 


\section{- Relacionadas con el área de LCL y Educación Física}

Tabla 9. Actividades LCL y Educación Física

\begin{tabular}{|c|c|c|c|}
\hline Actividades & $\begin{array}{c}\text { ¿Cómo realizaremos } \\
\text { la actividad? }\end{array}$ & $\begin{array}{l}\text { ¿Qué función cumple } \\
\text { el alumnado? }\end{array}$ & Conclusiones \\
\hline $\begin{array}{l}\text { 1. Calentamiento } \\
\text { animado }\end{array}$ & $\begin{array}{l}\text { Recordamos el cuento } \\
\text { y calentamos en base } \\
\text { a varios fragmentos. } \\
\text { Por ejemplo, } \\
\text { movimiento de } \\
\text { brazos al lanzar lejos } \\
\text { golosinas; hacer una } \\
\text { carrera huyendo de la } \\
\text { bruja; etc. }\end{array}$ & $\begin{array}{l}\text { Los niños comentarán } \\
\text { el cuento destacando } \\
\text { varias partes y } \\
\text { trabajaremos con ellos el } \\
\text { movimiento corporal. }\end{array}$ & $\begin{array}{l}\text { El objetivo de esta actividad } \\
\text { es el trabajo cooperativo } \\
\text { para comentar el cuento } \\
\text { entre todos y llevarlo al ám- } \\
\text { bito de la educación física, } \\
\text { fomentando buenos hábitos } \\
\text { motrices, deportivos y fo- } \\
\text { mento de valores. } \\
\text { - ¿Creen que Hänsel y } \\
\text { Gretel eran niños sanos y } \\
\text { fuertes? }\end{array}$ \\
\hline $\begin{array}{l}\text { 2. Juegos } \\
\text { cooperativos } \\
\text { (gymkhana) }\end{array}$ & $\begin{array}{l}\text { Realizar una serie } \\
\text { de pruebas para huir } \\
\text { de la bruja y llegar a } \\
\text { casa. }\end{array}$ & $\begin{array}{l}\text { Los alumnos pasarán por } \\
\text { una serie de retos físicos } \\
\text { haciendo referencia a } \\
\text { todos los obstáculos que } \\
\text { se encontraron Hänsel } \\
\text { y Gretel en el cuento: } \\
\text { un río, golosinas, una } \\
\text { paloma, la bruja... }\end{array}$ & $\begin{array}{l}\text { Debemos tener en cuenta las } \\
\text { características de cada alum- } \\
\text { no para llevar a cabo las prue- } \\
\text { bas en grupo para fomentar } \\
\text { las habilidades motrices. } \\
\text { - ¿Qué han aprendido al } \\
\text { trabajar en grupos? } \\
\text { - ¿Cuáles han sido las } \\
\text { dificultades presentadas? }\end{array}$ \\
\hline
\end{tabular}

Nota: Elaboración propia a partir del trabajo realizado por el alumnado.

\section{Resultados}

Los resultados del trabajo realizado por los diferentes grupos son positivos. Podemos apreciar en las actividades creadas por el alumnado (las mostradas a título de ejemplo y otras no expuestas) tanto la sinergia entre literatura, creatividad, emociones y educación física como la integración de estas en los respectivos currículos. Apreciamos, igualmente, el enfoque competencial que la dinámica promueve. He buscado, por un lado, que el aprendizaje sea significativo, que el alumnado lo relacione con sus saberes previos y lo implemente en base a la relación con otros saberes, que, además, parten de lo lúdico para consolidar dinámicas de aula creativas; por otro, que el alumnado sea competente en su futuro desempeño profesional, promoviendo nuevas líneas de actuación. Como exponen Alonzo Riveradiana et al. (2015, p. 78), debemos «replantear la labor de los docentes, quienes deberán diseñar procesos didácticos orientados a la formación inteǵral de los alumnos». Se sigue también los planteado por Lizitza y Sheepshanks 
(2020, p. 90) en relación con la necesidad de cambio en los currículos universitarios, que la innovación y la creatividad sean «dos competencias a considerarse como genéricas o transversales en los currículos, correspondientes a la formación de profesionales en los distintos campos del conocimiento».

\section{Conclusiones}

Creo haber cumplido tanto los objetivos expuestos en la introducción de este artículo como los vinculados a la asignatura, entre los que destacamos (Caballero Ramírez et al., 2013, p. 11):

- Despertar en el alumnado de grado la sensibilidad hacia diferentes manifestaciones artísticas.

- Diseñar sesiones de trabajo, estrategias y recursos en el aula de Educación Primaria para potenciar la creatividad de los niños en las que se utilicen recursos interdisciplinares.

- Favorecer la reflexión y la lectura en el alumnado.

Este tipo de propuestas propician una visión interdisciplinar, la creatividad de los futuros docentes y el trabajo en equipo. Todo ello redundaría en un aprendizaje más abierto y participativo. El alumnado que ha participado en la experiencia agradece que nos hayamos adentrado en la literatura, en la estética, desde su formación específica: la educación física. Damos sentido así a las palabras de Guimarães Botelho (2009) en relación con las posibilidades que la literatura ofrece en el área de Educación Física:

Para el niño, la literatura infantil es la posibilidad de creación de sentidos como el de reflexión y construcción de sí mismo, es decir, una autocreación dirigida al proceso de socialización, al contacto con el otro niño, con el adulto o con una persona mayor, y a los cambios generados por ese contacto (p. 90).

\section{Referencias}

Aguilar, L. (Autora) y Neves, A. (Ilustrador). (2008). Orejas de mariposa. Kalandraka.

Alonzo Riveradiana, D. L., Valencia Gutiérrez, M. del C., Vargas Contreras, J. A., y Bolívar Fernández, N. del J. (2015). Estrategias para el desarrollo de competencias en el aula, con enfoque formativo. Boletín Virtual, 4(9), 77-85. https://dialnet. unirioja.es/descarga/articulo/6232397.pdf

Armstrong, T. (2006). Las inteligencias múltiples en el aula: guía práctica para educadores. Paidós Educador. 
Andreae, G. (Autor) y Parker-Rees, G. (Ilustrador). (1999). Las jirafas no pueden bailar. Bruño.

Ausubel, D. P. (2002). Adquisición y retención del conocimiento. Una perspectiva cognitiva. Paidós.

Caballero Ramírez, S., Correa Santana, J. L., Perera Santana, A., Sánchez García, M., Suárez Robaina, J. R., y Suárez Vega, B. (2013). Educación literaria y estética en la enseñanza primaria. Manuales Docentes Grado en Educación Primaria, 29. Universidad de Las Palmas de Gran Canaria, Vicerrectorado de Profesorado y Planificación Académica.

Ciraolo, S. (2014). Abrázame. SM.

Conde, J., Arteaga, M., y Viciana, V. (1998). Interdisciplinariedad de las áreas en educación primaria. La Educación Física refuerzo del área de lengua castellana y literatura. Apuntes de Educación Física y Deportes, 51, 46-54.

Decreto 89/2014, de 1 de agosto, por el que se establece la ordenación y el currículo de la Educación Primaria en la Comunidad Autónoma de Canarias. Boletín Oficial de Canarias, 156, de 13 de agosto de 2014, 22353-22412. http://www.gobiernodecanarias.org/boc/2014/156/001.html

Guimaraes Botelho, R. (2009). ¿Qué puede aportar la literatura infantil a una Educación Física para la paz? «La Peonza». Revista de Educación Física para la Paz, 4, 87-95. https://www.researchgate.net/publication/44813731_Que_puede_aportar_la_literatura_infantil_a_una_Educacion_Fisica_para_la_paz

Guimaraes Botelho, R. (2017). Los libros sobre Deportes y el fomento de la lectura en el currículo de Educación Física: un análisis del libro de Arthur G. Miller y Virǵinia Whitcomb (1957). Revista Iberoamericana de Educación / Revista Ibero-americana de Educação, 75(2), 59-70. https://doi.org/10.35362/rie7522632

Lizitza, N., y Sheepshanks, V. (2020). Educación por competencias: cambio de paradigma del modelo de enseñanza-aprendizaje. RAES, 12(20), 89-107. http://www. revistaraes.net/revistas/raes20_art6.pdf

McKee, D. (2018). Elmer. Beascoa.

Parra Luque, J. A. (2008). Animación a la lectura a partir del área de Educación Física (los cuentos motores). Revista Digital, 13, 122. https://www.efdeportes.com/ efd122/animacion-a-la-lectura-a-partir-del-area-de-educacion-fisica.htm

ProFamilia (Autor) y Geisler, D. (Ilustrador). (2015). ;Mi cuerpo es mío! Juventud.

Rebel, G. (2000). El lenguaje corporal. EDAF.

Ruiz-Omecaña, J. V. (2009). Cuentos motores cooperativos para la educación primaria. Ljsalfar y los niños del viento. Inde.

Ruiz-Omecaña, J. V. (2011). El cuento motor en la educación infantil y en la educación física escolar. Wanceulen editorial deportiva.

Rodari, G. (1979). Gramática de la fantasía. Reforma de la escuela.

Salas Díaz, M. (2008). Elogio de la escritura creativa en la clase de E/LE. Ogigia, revista electrónica de estudios hispánicos, 4, 47-58.

Tabernero Sánchez, B., Aliseda García, B., y Daniel Huerta M. J. (2016). ¿Jugamos a los cuentos? Una propuesta práctica de animación a la lectura a través de la Educación Física. Retos, 29, 216-222. https://doi.org/10.47197/retos.v0i29.40963 